\title{
Carpal boss: a sonographic view
}

\author{
Bossa carpal: numa visão ultrassonográfica
}

Marcelo Novelino Simão ${ }^{1}$

Mass on the dorsal aspect of the wrist, either with or without associated pain, is a frequent complaint in orthopedic surgeon daily practice $^{(1)}$. In such cases, synovial or ganglion cyst is the most common diagnosis, but this is not the only diagnosis for that condition, so it is very important to know the differential diagnoses.

Dorsal wrist mass may originate from soft tissues and in such cases the differential diagnoses include ganglion cyst, soft tissue calcifications, tendon sheath giant cell tumor, lipoma and neuroma, amongst other possible small tumors. However, the mass may result from bone changes including small tumors such as osteochondromas, osteomas, degenerative changes with marginal osteophytes and presence of an accessory ossicle such as the os styloideum ${ }^{(\mathbf{1 , 2})}$.

Carpal boss is a bone protuberance located adjacent to the base of the second or third metacarpal bone, adjacent to the capitate or to the trapezoid, resulting from degenerative alterations with osteophytes at the base of the second or third metacarpal bone, from the presence of an accessory ossicle (os styloideum), or both ${ }^{(2,3)}$. Generally, the symptomatic presentation of this condition, with pain, for example, is observed in individuals at the fourth decade of life, but it may also affect children and adolescents ${ }^{(4)}$. Although the determination of a bony prominence on the dorsal wrist is subjective and there is no absolute criterion to establish the diagnosis, a study involving cadavers dissection have found bony prominence in 39 out 202 dissected wrists, most frequently between the second metacarpal and the trapezoid bones ${ }^{(5)}$.

Clinical diagnosis may be difficult and imaging methods can give a significant contribution in these cases. Plain radiography is quite useful, but it is important to note that the accessory ossicle is not always clearly seen at conventional or routine wrist radiography, and further imaging in specific planes are required ${ }^{(2)}$. Due to their sectional nature, computed tomography and magnetic resonance imaging can greatly facilitate the identification of the accessory bone or the degenerative disease ${ }^{(6)}$. Because of its great soft tissue contrast capability, magnetic resonance imaging can detect alterations in signal with a pattern of edema which may result from biomechanical alterations caused by repeated trauma ${ }^{(6)}$ in association with the presence of symptoms.

A brief literature review on PubMed has not identified any study associating the diagnosis of carpal boss with ultrasonography, although this imaging method is frequently utilized to investigate the

1. PhD, MD, Radiologist, Central de Diagnóstico de Ribeirão Preto (Cedirp), Physician Assistant at the Unit of Musculo-skeletal Radiology, Center of Imaging and Medica Physics - Hospital das Clínicas da Faculdade de Medicina de Ribeirão Preto da Universidade de São Paulo (HCFMRP-USP), Ribeirão Preto, SP, Brazil. E-mail: marcelo_simao@hotmail.com. wrist in the daily practice, including for complaints of dorsal mass or prominence with clinical suspicion of synovial or ganglion cyst which represent the most important differential diagnoses for carpal boss.

The study developed by Arend ${ }^{(7)}$, published in the present issue of Radiologia Brasileira, is interesting because it approaches an uncommon diagnosis of a common clinical condition - a diagnosis that many times is made by a radiologist facing a different clinical suspicion -, and also because the diagnosis is made by ultrasonography, a method that is quite frequently utilized to investigate wrist conditions, but is practically ignored in the literature about the carpal boss diagnosis. As the author approaches this subject and utilizes ultrasonography as a diagnostic method, he greatly contributes to the development of imaging diagnosis.

For radiologists and other practitioners which utilize ultrasonography as a diagnostic tool, such studies approaching new frontiers for the investigation of situations where the role of the method is not very well recognized, like in the diagnosis of labrum shoulder tear $^{(\mathbf{8})}$ or meniscal extrusion ${ }^{(9)}$, are extremely important to disseminate new knowledge and to demonstrate the diagnostic potential of ultrasonography, either isolatedly or combined with other imaging methods.

In the mentioned study, Arend ${ }^{(7)}$ clearly and objectively goes into detail on the concept of carpal boss and its physiopathogenesis, describing the technique for the sonographic diagnosis, including correlations between clinical, radiographic and, obviously, sonographic images.

\section{REFERENCES}

1. Boggess B, Berkoff D. Dorsal wrist mass: the carpal boss. BMJ Case Rep. 2011;2011.pii: bcr0120113695. doi: 10.1136/bcr.01.2011.3695.

2. Conway WF, Destouet JM, Gilula LA, et al. The carpal boss: an overview of radiographic evaluation. Radiology. 1985;156:29-31.

3. Park MJ, Namdari S, Weiss AP. The carpal boss: review of diagnosis and treatment. J Hand Surg Am. 2008;33:446-9.

4. Capo JT, Orillaza NS, Lim PK. Carpal boss in an adolescent: case report. J Hand Surg Am. 2009;34:1808-10.

5. Alemohammad AM, Nakamura K, El-Sheneway M, et al. Incidence of carpal boss and osseous coalition: an anatomic study. J Hand Surg Am. 2009;34:1-6.

6. Gomes AF, Paganella VC, Paganella MC, et al. Achados de imagem por tomografia computadorizada e ressonância magnética do os styloideum em atleta sintomático. Radiol Bras. 2010;43:207-9.

7. Arend CF. Revisão sobre as diferentes apresentações da bossa carpal na ultrassonografia. Radiol Bras. 2014;47:112-4.

8. Simão MN, Nogueira-Barbosa MH, Muglia VF, et al. Anterior shoulder instability: correlation between magnetic resonance arthrography, ultrasound arthrography and intraoperative findings. Ultrasound Med Biol. 2012;38:551-60.

9. Nogueira-Barbosa MH, Gregio-Junior E, Lorenzato MM, et al. Ultrasonographic assessment of medial meniscal extrusion: a validation study using magnetic resonance imaging (MRI) as the reference standard. ECR 2013. doi: 10.1594/ecr2013/ C-1903. 